\title{
Reducing Repeat Offending Through Less Prosecution in Victoria, Australia: Opportunities for Increased Diversion of Offenders
}

\author{
David Cowan, et al. [full author details at the end of the article]
}

Published online: 7 November 2019

(C) The Author(s) 2019

\section{Abstract}

Research Question How did the use of diversion from prosecution and criminal sentencing change in Victoria, Australia, in the 10 years to 2016/2017, with what estimated effects on repeat offending?

Data We tracked 1,163,113 criminal cases brought against both juveniles and adults by police in the state of Victoria, Australia, including 181,836 diversions, during the 10year time period from the fiscal year of 2007/2008 through 2016/2017.

Methods Taking the percentage of all cases diverted in the first year $(25.6 \%)$, we calculated for each of the study years how many more cases would have been diverted from prosecution across the subsequent 9 years if the diversion rate had stayed the same ("missed opportunities"). We multiplied the estimated number of these "missed opportunities" by the reduced frequency of repeat offences that the prosecuted offenders were likely to have committed, after adjusting for the time at risk by the number of years left in the study period. Then, based on a systematic review of diversion experiments (Petrosino et al. 2010), we applied the standardised effect size of diversion in those studies to Farrington's (1992) annualised crime frequency per 100 offenders aged 25, multiplying that effect across all of the person-years after a case was prosecuted rather than diverted, using both population-based rates and rates based only on detected offenders at that age.

Findings The diversion rate in Victoria dropped in half over 10 years, from $25.6 \%$ to $12.5 \%$. The total missed opportunities for diversion, compared to the counterfactual of applying diversion at a constant rate of $25 \%$ over that time period, totalled 115,885 cases over the 10 years. Taking an average effect size $(d=-0.232)$ across seven experiments with a mean follow-up time of 12-13 months, as derived from a systematic review of diversion experiment outcomes, our illustrative estimate is that at least 8 crimes per year per 100 offenders could have been prevented among the missed opportunity cases. Using a population rate of offending, the estimate equals 1474 crimes that could have been prevented. Using the offending population rate, we estimate that 37,050 offences could have been prevented.

Conclusions While the exact amount of crime prevented remains speculative, the application of best evidence to the missed opportunity cases suggests that more diversion could have resulted in substantially less repeat offending, and hence less total crime. 
Keywords Arrest · Prosecution · Diversion · Prevention · Juveniles $\cdot$ Recidivism

\section{Introduction}

The decision not to prosecute in the public interest is a long-standing power of the constable. The decision to work out an informal resolution between the offender and the victim, "outside the King's justice," has centuries of precedent. The simple view that "police investigate" and "courts decide" is manifestly inaccurate (Sherman and Neyround 2012; Slothower et al. 2015).

As UK Attorney General Sir Hartley Shawcross said in 1951, "it has never been the rule in this country, and I hope it never will be, that suspected criminal offences must automatically be the subject of prosecution" (House of Commons Debates 1951). He went on to outline the importance of public interest considerations having regard to the circumstances of offending. In Australia, the current Victorian Prosecutorial Guidelines (Office of Public Prosecutions 2018) contain such a consideration, whereby the prosecution may only proceed if it is in the public interest to do so. As Petrosino et al. (2010) observe, police have tremendous discretion on how to handle offenders and can decide whether they should be officially processed by the justice system or diverted from it. They offer strong empirical evidence that these police decisions about diversion can prevent or cause crime for years to come.

Police use of diversion affects not only offenders. It also affects victims, police resources and the costs of the criminal justice system (Neyroud 2018). Any changes to criminal justice processing and police practices yield large ripple effects. For police or government to change policy, the evidence that an approach works should be clear (Laycock and Mallender 2015), especially in the precise ways it has been tested. Although diversion offers the possibility of great benefits if implemented well, if implemented poorly, diversion can present a range of risks (Slothower 2014). The use of diversion is often subject to debate for both technical and "social climate" reasons.

This article provides a case study of changing diversion practices in a context of social reactions to perceptions of rising crime and major increases in the number of police officers. It documents the trends in reduced use of diversion per 100 offenders. It also estimates the number of crimes that could have been prevented had the diversion rate not been reduced, based on an international systematic review (including Australian studies) of the effects of diverting juveniles from prosecution.

\section{Diversion in Victoria, Australia}

Diversion as a criminal justice policy has been a highly contested issue in the Australian state of Victoria in recent years, where the entire criminal justice system has been under increasing pressure. An additional 1700 police had been deployed as of 2015, and 3135 more were planned to be deployed over the subsequent 4 years (Victorian Government 2017). Weekend courts have been introduced, 18 new magistrates assigned and 98 million dollars earmarked for additional police prosecutors, all as a direct result of the increasing demands on the criminal justice system. Over the 
decade ending in 2017, the prisoner population in Victoria has increased by $71 \%$ (Justice and Regulation 2017).

Little discussion, however, has addressed the question of whether research evidence supports the effectiveness of a rapid increase in prosecutions and imprisonment in order to reduce crime or at least repeat offending. If there are alternative responses that may be more effective in reducing crime, they would logically deserve consideration. Given the evidence of the most recent systematic review on diversion, as well as other sources, diversion may produce less crime than prosecution. The intention of this study, therefore, is to track Victorian data for opportunities to target more police diversion for crime prevention. If such targets can be identified, they could constitute opportunities to relieve the pressure on prosecution, courts and even prison. At best, diversion may also succeed in saving more early-stage offenders from a life of crime.

The main limitation of this article is that it is limited to estimating the individual effects of sanction decisions on the sanctioned, that is, their specific deterrent effects. The question of whether increased prosecutions and imprisonment yield a general deterrent effect that can reduce crime across the entire state, and not just among arrested offenders, is beyond the scope of the present analysis - either in Victoria or elsewhere. Nonetheless, if the evidence indicates a substantial likelihood of increasing the offending of those sanctioned, that would imply an even greater need for a general deterrent effect to make up for an increase in crime at the individual level of analysis.

\section{Research Question}

Our primary research question concerns the way that the use of diversion from prosecution and criminal sentencing changed in Victoria, Australia, in the ten fiscal years to 2016/2017, and with what estimated effect on repeat offending. The study's task is to provide a clear measurement of these changes, in order to estimate the number of people who would have been diverted had the rates of diversion per 100 cases stayed the same from 2006/2007 through 2016/2017.

\section{Data}

Our data consist of 1,163,113 crime cases brought against both juveniles and adults by police in the state of Victoria, Australia, including 181,836 that resulted in diversions, during the 10-year time period from fiscal years 2007/2008 through 2016/2017. Data on these cases were drawn by the first author from Victoria Police, the Victoria Crime Statistics Agency (CSA), the Magistrates' Court, the Children's Court and the Sentencing Advisory Council.

\section{Methods}

Long-term annual trends for police diversion (both adults and children) over 10 years were examined, as a proportion of charged offenders. The overall rate of police diversion from prosecution was calculated by combining the total number of alleged 
adult and child offenders charged and processed by police (as the denominator) compared to the total number within that group of alleged offenders who were diverted (as the numerator).

The "missed opportunities" for diversion were calculated year-on-year by subtracting the actual number of cases diverted in each year from the calculated total of diversion cases that there would have been if the proportion of cases diverted that year had remained constant at the 2007/2008 level. The result of that subtraction is interpreted as the number of additional cases which could have been eligible for diversion.

The procedure we used assumes a constant distribution within each year of the seriousness of criminal charges, the prior records of defendants and other characteristics that helped to cause cases to be seen by police as "eligible" for diversion at the start of the time period relative to all 9 years thereafter. That assumption may be more or less incorrect, but we have no viable alternative to making that assumption absent a local crime harm index. Moreover, the evidence suggests that the social context of those decisions did not remain constant in public debates over crime, and that plunging diversion rates were at least partly responsive to the political climate and media attention to the crime problem. Hence, this analysis, like many models, depends on a working assumption that can help to chart a plan of analysis and provoke further research.

\section{Findings}

\section{Declining Use of Diversion}

Table 1 shows the annual numbers of offenders charged and diverted by the Victoria Police over the 10-year period, combining both adult and child offenders. The bottom line in italics shows the raw numbers of extra persons who would have been diverted had the percentage of cases diverted in the baseline year of 2007/2008 held steady through the full 10-year series. Because the percentage of cases diverted in every year after 2007/2008 was lower than in that baseline year, the number of cases that could have been diverted under the baseline percentage is always a positive number. Given the evidence about the crime-preventive effects of diversion as compared to prosecution, we call these cases that could have been diverted "missed opportunities."

The table sums across all years the raw number of "missed opportunities" to divert cases at the rate of diversions in the baseline year. This sum is presented in the lower right-hand corner of the table: 115,885 out of the total of $1,163,113$. Thus, almost $10 \%$ of all 1.1 million cases processed over that decade were prosecuted, rather than diverted, as a consequence of the steadily declining proportion of all cases prosecuted from 2007 through 2017.

Some of the cases presented in Table 1 could have involved the same individuals, both within and across years. The analysis is therefore challenged to estimate the effect of not one, but potentially several, decisions to prosecute rather than to divert individual people. The rates of change, and even direction, in likelihood of diversion, may have varied by offence type, as well as demographic characteristics and other variables. Thus the information in Table 1 is very limited but very clear. Over a recent decade, Victoria Police substantially and steadily reduced their use of diversion for dealing with people accused of crimes. 


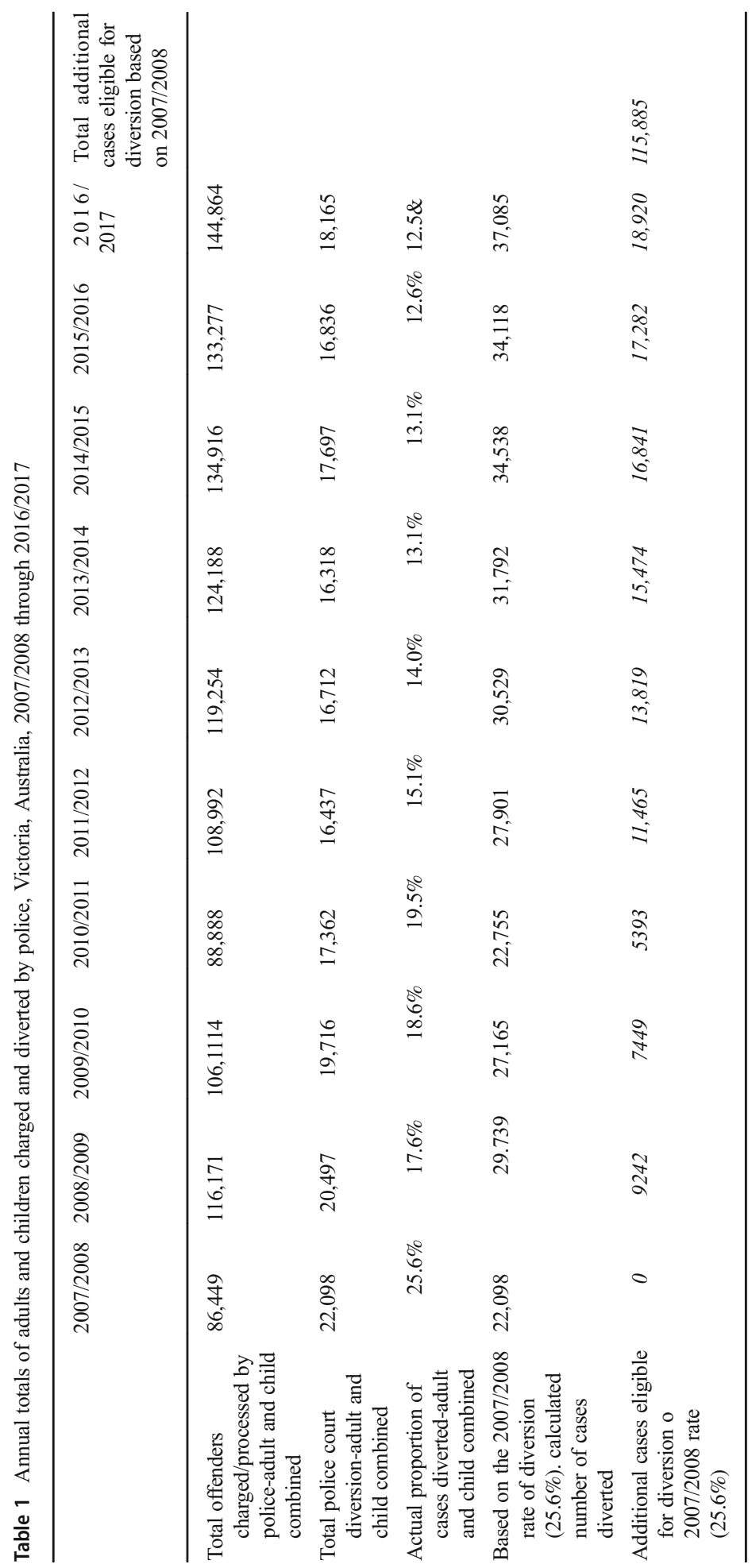




\section{Two Estimates of Effects on Recidivism}

The best estimate of what effect the declining use of diversion had on repeat offending rates comes from an international systematic review of randomised trials of diversion of juveniles from prosecution (Petrosino et al. 2010: Fig. 4). No comparable review is available for experiments in diverting adults from prosecution. As the best available heuristic, we apply the Petrosino et al. (2010) estimated effect size of the benefits from diverting offenders compared to prosecuting them. Expressed in terms of a standardised mean difference across the seven tests summarised in a meta-analysis called a "forest plot," the effect size found by the review was $d=-0.232,95 \%$ confidence intervals $=$ $0.405-0.059, p=0.008$. That means that across the seven studies, the average effect of diversion of juveniles was to reduce the frequency of repeat offending over a follow-up period of 9-10 months.

Translating the abstract meaning of the "standardized mean difference" into an actual count of crimes is a challenging task, for many reasons. One is that the majority of the population studied were adults, while the estimated benefits of diversion come from studies of juveniles. Second, juveniles tend to have higher frequency of offending per year than adults (Farrington 1992, Table 1). Third, any population of offenders is heterogeneous as to offence frequency (e.g. Liggins et al. 2019), with a small percentage of offenders producing a high volume of offences, and others producing a high proportion of all crime harm. Fourth, we have no evidence on whether the offending frequency or seriousness of the offender population in 2007/2008 was higher or lower than in later years.

For all these reasons, we do not attempt a precise estimate of exactly how many crimes, or how much crime harm, could have been prevented by using diversion in the same proportion of all cases in all years as in the baseline year of 2007/2008. Instead, we merely offer an illustration of how the effect size of the crime-preventive benefits of diversion from the field experiments with juvenile offenders could be applied to the entire population.

With a standardised mean difference between prosecuted and diverted cases (Cohen's $d$ ) of -0.2 , as reported in Petrosino et al. (2010, Fig. 4), 58\% of the diversion group will be above the mean of the non-diverted group (Cohen's $\mathrm{U}_{3}$ ), $92 \%$ of the two groups will overlap, and there is a $56 \%$ chance that a person picked at random from the diversion group will have a higher score than a person picked at random from the non-diverted group (probability of superiority). This means that if 100 people go through diversion, 8 more people will have a favourable outcome compared to diverted (if we assume a 50/50 success rate for both groups). These conclusions are drawn from several sources on translating effect sizes into different metrics (Farrington and Loeber 1989; Lipsey and Wilson 2001; Ruscio et al. 2008; Ruscio et al. 2012). ${ }^{1}$

The estimated amount of crime prevented then becomes highly sensitive to the assumption about the base rate of offending. In Table 2, we present results based on two different

\footnotetext{
${ }^{1}$ To a good approximation $d=2 * r$ and $r=$ the absolute difference in the fraction who have successful outcomes (less repeat offending). Thus, in a very conservative calculation, if $d=0.2$, the difference is 0.8 . If we assume, for example, a 50/50 success rate for both groups, the treatment group has $56 \%$ success versus $44 \%$ in the control group.
} 
Table 2 Estimated preventable offences with a constant $25 \%$ rate of diversion for both population and offender rates of recorded offences per annum (Farrington 1992: Table 1)

\begin{tabular}{|c|c|c|c|c|c|c|}
\hline Year & $\begin{array}{l}N \text { of missed } \\
\text { opportunities }\end{array}$ & $\begin{array}{l}N \text { of years } \\
\text { after miss }\end{array}$ & $\begin{array}{c}\text { Misses } \times \\
\text { years after }\end{array}$ & $\begin{array}{l}\text { Estimated } \\
\text { crime per } \\
\text { year at } 5 \\
\text { crimes } \\
\text { per } 100\end{array}$ & $\begin{array}{l}\text { Estimated } N \\
\text { of crimes } \\
\text { prevented } \\
(0.08) \text { by } 25 \% \\
\text { Diversion at } 5 \\
\text { per } 100 \\
\text { (population) }\end{array}$ & $\begin{array}{l}\text { Estimated } N \text { of } \\
\text { crimes prevented } \\
(0.08) \text { by } 25 \% \\
\text { diversion } \\
\text { at } 125 \text { per } \\
100 \text { (offenders) }\end{array}$ \\
\hline $2007 / 2008$ & 0 & 9 & 0 & 0 & 0 & 0 \\
\hline $2008 / 2009$ & 9242 & 8 & 73,936 & 3696.8 & 296 & 7400 \\
\hline $2009 / 2010$ & 7449 & 7 & 52,143 & 2607.15 & 209 & 5225 \\
\hline $2010 / 2011$ & 5393 & 6 & 32,358 & 1617.9 & 129 & 3225 \\
\hline $2011 / 2012$ & 11,465 & 5 & 57,325 & 2866.25 & 229 & 5725 \\
\hline $2012 / 2013$ & 13,819 & 4 & 55,276 & 2763.8 & 221 & 5725 \\
\hline $2013 / 2014$ & 15,474 & 3 & 46,422 & 2321.1 & 186 & 4650 \\
\hline $2014 / 2015$ & 16,841 & 2 & 33,682 & 1684.1 & 135 & 3375 \\
\hline $2015 / 2016$ & 17,282 & 1 & 17,282 & 864.1 & 69 & 1725 \\
\hline $2016 / 2017$ & 18,920 & 0 & 0 & 0 & 0.0 & 0 \\
\hline $\begin{array}{l}\text { Sum of all } \\
\text { years }\end{array}$ & & & & & 1474 & 37,050 \\
\hline
\end{tabular}

assumptions. The first is extremely conservative, in which we use the population rate of offending at age 25 among the 411 subjects of the Cambridge Study of Delinquency Development (Farrington 1992: Table 1). The age of 25 is selected because it is close to a usual midpoint in the age of offending across offenders of all ages. Yet not all, or even most, people of that age are offenders. Farrington's data show that only 15 of the 411 had a recorded offence at age 25 , and those 15 had a record of 20 offences in all. That rate of offending per offender is substantially higher (125 crimes per year per 100 offenders) than the rate of offending per (male) citizen ( 5 per 100). The rate of offences per offender is 25 times higher than the population rate. Hence, the estimate for the number of offences preventable by diversion is 25 times higher as well. In both cases, we apply the translation of the estimated effect size of -0.2 into a conservative $8 \%$ reduction in the estimated rate of offending.

The estimate of 1474 offences prevented based on a population rate of offending is extremely conservative since it assumes no elevation at all in the offending rates of offenders over non-offenders in the population of 25-year-olds of the 411 Cambridge subjects in the UK in the mid-1970s. The estimate of 37,050 offences prevented based on the offender population rate, on the other hand, may be too high, if only because the people still offending at age 25 in mid-1970s London might have been unusually prolific offenders relative to those in Victoria in the early twenty-first century. Whether or not that is true is difficult to gauge given different police and justice practices in each place and time. Nonetheless, the estimate is transparent and can be challenged by other evidence that would support a correction. 


\section{Conclusion}

Tracking the reduction in diversion in Victoria over this period provides an estimate of the number of people who would have been diverted had diversions per 100 cases stayed the same from 2006/2007 through 2016/2017. While the exact amount of crime prevented remains speculative, the application of best evidence to the "missed opportunity cases" suggests that if diversion rates had not collapsed, diversion could have resulted in thousands of crimes being prevented. The reduction by half in the rate of diversion in Victoria in the 10 years to 2016/2017 highlights the importance of ongoing tracking by police agencies of the rate of diversion, particularly in times where social, political or legal factors may have potential to erode the rate itself.

Open Access This article is distributed under the terms of the Creative Commons Attribution 4.0 International License (http://creativecommons.org/licenses/by/4.0/), which permits unrestricted use, distribution, and reproduction in any medium, provided you give appropriate credit to the original author(s) and the source, provide a link to the Creative Commons license, and indicate if changes were made.

\section{References}

House of Commons Debates, (1951) Volume 483, 29 (quote of: Hartley Shawcross).

Farrington, D. P., \& Loeber, R. (1989). Relative improvement over chance ( RIOC ) and phi as measures of predictive efficiency and strength of association in $2 \times 2$ tables. J Quant Criminol, 5(3), 201-213.

Farrington, D. P. (1992). Criminal career research in the United Kingdom. Brit J Criminology, 32, 521.

Laycock, G. and Mallender, J. (2015). 'Right method, right price; the economic value and associated risks of experimentation'. J Exp Criminol 11(4): 1-16.

Liggins, A., Ratcliffe, J.E. \& Bland, M. (2019). Targeting the most harmful offenders for an English police agency: continuity and change of membership in the "felonious few." Cambridge Journal of EvidenceBased Policing 3:3.

Lipsey, M. W., \& Wilson, D. B. (2001). Practical meta-analysis. Thousand Oaks: Sage Publications.

Neyroud P. W., (2018). Out of court disposals managed by the police: a review of the evidence. Commissioned by the National Police Chief's Council of England and Wales. University of Cambridge.

Office of Public Prosecutions, (2018). Director of Public Prosecutions, Prosecutorial Guidelines. Downloaded on 27th November, 2018 from: http://www.opp.vic.gov.au/Resources/Policies.

Petrosino, A., Turpin-Petrosino, C. and Guckenburg, S. (2010). Formal system processing of juveniles: effects on delinquency, Campbell Collaboration (Crime and Justice) Systematic Review. Retrieved 27th April 2018 from https://www.campbellcollaboration.org/library.

Ruscio, J. (2008). A probability-based measure of effect size: robustness to base rates and other factors. Psychol Methods, 13(1), 19-30.

Ruscio, J., \& Mullen, T. (2012). Confidence intervals for the probability of superiority effect size measure and the area under a receiver operating characteristic curve. Multivar Behav Res, 47(2), 201-223.

Sherman, L. W., \& Neyround, P. W. (2012). Offender desistance policing and the sword of Damocles. London: Civitas.

Slothower, M. P. (2014). Strengthening police professionalism with decision support: bounded discretion in out of court disposals. Policing, 8(4), 353-367.

Slothower, M., Sherman, L. W., \& Neyroud, P. (2015). Tracking quality of police actions in a victim contact program: a case study of training, tracking, and feedback (TTF) in evidence-based policing. International Criminal Justice Review, 25(1), 98-116.

Victorian Government, (2017). Community safety statement 2017. Retrieved on 27th November, 2018 from: https://communitysafety.vic.gov.au/media/1072/djr001_g_css01_lr.pdf

Publisher's Note Springer Nature remains neutral with regard to jurisdictional claims in published maps and institutional affiliations. 


\section{Affiliations}

David Cowan ${ }^{1} \cdot$ Heather Strang ${ }^{2} \cdot$ Lawrence Sherman $^{2} \cdot$ Sara Valdebenito Munoz $^{2}$

Heather Strang

hs434@cam.ac.uk

1 Victoria Police, Melbourne, Australia

2 Institute of Criminology, University of Cambridge, Cambridge, UK 